\title{
Assessment of sensory and physical-chemical quality, and potential for certification of cachaças from the state of Paraíba, Brazil
}

\author{
Anderson Ferreira VILELA ${ }^{1 \star}{ }^{\oplus}$, Líbia de Sousa Conrado OLIVEIRA², Marcelo Barbosa MUNIZ ${ }^{3}$, \\ Beatriz Cavalcanti Amorim de MÉLO ${ }^{4}$, Maria José de FIGUEIREDO${ }^{1}$, João de Mélo VIEIRA NETO ${ }^{4}$
}

\begin{abstract}
The State of Paraíba is an important producer of artisanal cachaça that has outstanding quality in national tasting panels and for this reason this research studied organizational aspects for certification and compliance with Good Manufacturing Practices - GMP - of 53\% of formal producers. Samples of cachaças from these producers were evaluated for physical-chemical and sensory quality by experienced tasters. Sixty-five percent of the cachaças evaluated met the legally determined physicalchemical quality parameters, but only $35 \%$ met the certification parameters. Evaluated the cachaça factories, on average, $85 \%$ of the GMP criteria were met. While, meeting the organizational criteria established for certification ranged from 48.1 to $82.4 \%$. The sensory evaluation of the cachaça samples indicated that the distillates from Paraíba should be subjected to longer storage times in wooden barrels, as they had a high alcoholic olfactory character, aroma related to solvent, burning and pungency and did not present intense oiliness, vanilla flavor and caramel. The results indicated that cachaça producers in Paraíba will have difficulties in obtaining the certification seal, since they only respected $66.4 \%$ of the organizational aspects of registration and mandatory control.
\end{abstract}

Keywords: sugarcane spirit; alembic; flavor profile.

Practical Application: There is a need for improving the quality of cachaças produced in the State of Paraíba, Brazil, as well as the procedures for their certification by regulatory bodies.

\section{Introduction}

The production of artisanal cachaça (distilled spirit made from fermented sugarcane) has been characterized by many regional and historical influences and, at the same time, gained increasing prominence as a differentiated drink, arousing the interest of increasingly demanding consumers in terms of quality. This new consumer profile has exerted pressure on cachaça production in order to qualify it, but maintaining the artisanal characteristic of the product, manufactured according to several quality criteria, including operational, hygienic-sanitary, food safety, sustainability, and fiscal/legal (Meneghim et al., 2017). Obviously, the drink should also generate sensory pleasure. This modern cachaça consumer made the national cachaça market - compared to those of other beverages in Brazil - exhibit greater growth in recent years in terms of value, and there is still great potential for increase (Oliveira et al., 2012).

Frequently, producing a good quality drink is not enough to win market, it is also necessary to prove to consumers the quality that this drink has in all aspects. This goal can be achieved by obtaining the certification awarded by regulatory bodies of recognized competence (Instituto Brasileiro da Cachaça, 2019). The certification process accumulates all the actions that the company should carry out in order to be entitled to a quality certificate. Consumer recognition of the drink quality assessment performed by a certifier is what values and justifies the certification process. In the area of food and beverages, we have a wide variety of quality certifications and certification bodies, such as: the AMPAQ seal (Minas Gerais Association of Quality Brandy Producers); the ABIC seal (Brazilian Coffee Industry Association); ABA certification (Brazilian Angus Beef Association); ISO (International Organization for Standardization) which certifies quality management systems (ISO 9.001) and environmental quality management (ISO 14.001); IBD (Biodynamic Institute) which certifies organic products; IMA (Agricultural Institute of Minas Gerais) which certifies artisanal cheeses and INMETRO (National Metrology Institute) which certifies a diversity of products, services and companies.

The State of Paraíba, Brazil, has stood out in this scenario. This is the state of the federation with the second largest production of artisanal cachaça. This Paraiba spirit drink has quality that draws attention in national tasting panels and, in terms of value, it is the cachaça that has the second highest average price 
among Brazilian states. Although in general numbers Paraíba is not a leader as an exporter of cachaça; it is the largest artisanal cachaça-exporting state in Brazil.

In this context, the goal of the present study was to assess the physical-chemical and sensory quality of cachaças produced in the Brazilian State of Paraíba, compliance with good manufacturing practices (GMP) requirements established by the Ministry of Agriculture, Livestock and Supply (MAPA), and compliance with the quality criteria of the National Institute of Metrology, Standardization and Industrial Quality (INMETRO) for certification purposes.

\section{Materials and methods}

\subsection{Sample collection}

The thirty-eight cachaças and spirits production facilities from the State of Paraíba, Brasil, holding active registration with the Ministry of Agriculture, were invited to participate in the present study. However, only twenty of them participated, given that six did not accept to participate, eight did not meet the legal criteria for the purposes of cachaça certification - such as selling only bottled cachaça, and not selling cachaça without the industrialized product tax seal - and four were not working in the harvest during which this study was conducted. These twenty cachaça industries were visited by the researchers and in each industry several bottles of cachaça from the same batch were collected to total three liters of sample for purposes of physical-chemical and sensory evaluation.

\subsection{Physical-chemical analysis}

The cachaça samples were subjected to quantification of compounds of mandatory determination (Brasil, 2005a) at the Laboratory of Pesticides and Contaminants in Food and Alcoholic Beverages of the Technological Institute of Pernambuco. The number of replicates used was that determined in each methodology.

The levels of copper, arsenic, and lead in the cachaça samples were determined by means of an atomic absorption spectrometer with atomization in a graphite furnace (Thermo Electron, model GFS97) with deuterium-lamp background correction, autosampler (FS97), and tube graphite with longitudinal heating and pyrolytic coating. The following hollow cathode lamps (Photron $^{\circledR}$, Tokyo, Japan) were used as radiation sources, in amperages and wavelengths: As (8 mA, $193.7 \mathrm{~nm})$; $\mathrm{Pb}(4 \mathrm{~mA}$, $283.3 \mathrm{~nm})$; and $\mathrm{Cu}(4 \mathrm{~mA}, 226.6 \mathrm{~nm})$. Argon (99.99\%, White Martins) was used as a purge gas at a flow rate of $200 \mathrm{~mL} / \mathrm{min}$. The quantification of these metals was carried out by comparing the absorbances observed in the samples of cachaça, with values referring to a calibration curve previously constructed from stock solutions of these metals (Brasil, 2005b - method NB 001/01).

The analysis of ethyl carbamate was performed using a thermo gas chromatograph (Trace GC Ultra) coupled to a mass spectrometer (Thermo ISQ), equipped with an autosampler (AS 3000), operating in the electronic impact mode with ionization energy at $70 \mathrm{eV}$, and monitoring of selective ions of ethyl carbamate. A Carbowax 20 chromatographic column $(60 \mathrm{~m} \times 0.32 \mathrm{~mm} \times 1.0 \mu \mathrm{m})$ was used as a stationary phase. The injector and detector interface temperatures were 250 and $230{ }^{\circ} \mathrm{C}$, respectively. The injection volume of each cachaça was $1 \mu \mathrm{L}$ in 'splitless' mode. The carrier gas used was helium, with a flow rate of $1.5 \mathrm{~mL} / \mathrm{min}$ (Instituto Adolfo Lutz, 2008 - method 229/IV).

The identification and quantification of secondary components and organic contaminants (ethyl acetate, acetaldehyde, furfural, isobutyl alcohol, isoamyl alcohol, n-propyl alcohol, acrolein, methyl alcohol, sec-butyl alcohol and n-butyl alcohol) were determined using a gas chromatograph (Thermo), with flame ionization detector (CG/FID), equipped with an autosampler (AS 3000) (Brasil, 2005b - method NB 001/01). A Carbowax 20M column $(60 \mathrm{~m} \times 0.25 \mathrm{~mm} \times 1.0 \mu \mathrm{m})$ was used with helium as carrier gas with a constant flow of $1.5 \mathrm{~mL} / \mathrm{min}$, and injector and detector temperatures of 230 and $250{ }^{\circ} \mathrm{C}$, respectively. The injected volume of cachaça for each sample was $1 \mu \mathrm{L}$ in splitless mode.

\subsection{Assessment of good manufacturing practices}

The facilities producing cachaça were assessed for hygienic-sanitary conditions and GMP using the checklist of the Inspection and Plant Surveillance and Protection Service of the Agricultural Defense Department, Ministry of Agriculture, Livestock and Supply (MAPA), as an instrument for the analyses. Each item of the check list was assessed by on-site inspection, searching for documents in the visited facilities and/or through interviews with employees, owners, and/or technicians responsible for the facilities. Items that met the legal requirements regarding GMP were computed as 'compliance'. Those that were not in accordance with legal determinations were considered 'non-compliance', and those that could not be assessed due to the non-applicability of the operation under analysis were considered as 'not applicable'.

\subsection{Assessment of potential for INMETRO certification}

Alembic cachaça factories were assessed for compliance with the precepts established by INMETRO for certification of cachaça. For the purpose of facilitating the assessment when visiting cachaça factories, the content of the Cachaça Conformity Assessment Regulation of the National Cachaça Certification Plan (Brasil, 2009) was transformed into a checklist similar to that used by MAPA. Similar to the previous assessment, the items also audited by inspection, interviews and/or consultation of documents were classified as 'Yes' (compliant), 'No' (not compliant), and N/A (not applicable), according to the methodology proposed by Coutinho et al. (2012).

\subsection{Assessment of sensory quality}

Sensory evaluation were performed at Amazile Biagioni Maia Laboratory, in Belo Horizonte, State of Minas Gerais, Brazil, with experience in sensory analysis of cachaças. Eight trained tasters from the Cachaça Sommeliers Association of Minas Gerais were recruited and selected. The team of judges was composed of five men and three women, with ages ranging from 22 to 60 years. Given that the assessments were carried out by human beings as measuring instruments, the research project was submitted to the Research Ethics Committee of the Federal University 
of Campina Grande (UFCG), and approved under Approval Certificate CAAE No. 71797317.0.0000.5182.

The judges were informed about the general objectives and frequency of the tests. They were adopted and trained according to the Dornelles et al. (2009) methodology in the recognition of primary odors and flavors and in the correct use of descriptive terminology. The judges' training took place at the ASC-MG premises, and the samples were assessed at Amazile Biagioni Maia Laboratory, at individual tables for each judge (Bortoletto et al., 2016).

The assessments of the cachaça samples were performed in four sessions, each of which dealt with the evaluation of five samples of cachaças according to the methodologies proposed by Duarte et al. (2012) for quantitative descriptive analysis. From this procedure, a spreadsheet was generated with the definition of descriptive terms (Duarte et al., 2012; Rota et al., 2013). The assessment environment had natural lighting complemented by white artificial light and a temperature of $22^{\circ} \mathrm{C}$. The samples provided to the tasters were served in coded ISO glasses, in a volume of $15 \mathrm{~mL}$. Between tasting the samples, the tasters consumed water and French bread to clean the palate. With the aid of a final form for evaluating the descriptors, each descriptor of each sample was graded from zero (corresponding to weak) to nine (corresponding to strong).

\subsection{Statistical treatment}

The results of the sensory assessments were grouped by geographic location, number of failed parameters in the physical-chemical analysis, and productive capacity, to later be submitted to analysis of variance (completely randomized block design). Pearson's chi-square test $\left(\chi^{2}\right)$ was used for expression of results. The interrelation of quality linked to GMP and INMETRO, and laboratory and sensory analysis were performed using Pearson's linear correlation coefficient method. Significance $\alpha$ $=0.01$ was used in the R software (R Core Team, 2018) to assess these statistical treatments

Due to the high number of treatments (20), and coefficient of variation and repetitions (8) in the sensory assessment, it was made analysis of variance (ANOVA) and comparison of means were performed using Student-Newman-Keuls (SNK) test.

\section{Results and discussion}

Of the thirty-eight legally active cachaça and spirits production facilities in the State of Paraíba, Brazil, only two (5.3\%) distilled by means of column-stills; the others performed it by means of copper alembics. These two distilleries did not bottle the cachaça produced, selling the drink to third parties to perform their own standardization, packaging, and labeling. Among the thirty-eight producers in Paraíba, three were drink standardizers, i.e., they purchased cachaça or brandy from different suppliers to make quality, bottling, and labeling adjustments. The capacity for cachaça production among the twenty facilities that participated in the present study was quite heterogeneous, varying from 20 thousand to 6 million liters per harvest, with an average of 767 thousand liters/year. However, the total annual capacity of 15.7 million liters/year was concentrated in two producers that together manufactured 10 million liters/year.

\subsection{Physical-chemical quality}

The results of the physical-chemical analyses of the cachaça samples are illustrated in Table 1. It is observed that, subtracting the percentages of uncertainty of each method from the values obtained, seven samples (35\%) did not meet the physical-chemical quality parameters established by the Ministry of Agriculture. This result is similar to that of Santiago et al. (2015), which verified that 22.1 to $38.5 \%$ of 396 cachaças samples in Minas Gerais met limits established by legislation. The Volpe et al. (2013) survey with cachaças from the northern region of the state of Paraná showed similar results, with $33.3 \%$ of the cachaça samples in disagreement with official parameters. As the limits determined by INMETRO for certification purposes were different from those established by the Ministry of Agriculture concerning the parameters volatile acidity $(100 \mathrm{mg} / 100 \mathrm{~mL}$ anhydrous alcohol) and ethyl carbamate $(150 \mu \mathrm{g} / \mathrm{L})$, thirteen samples (65\%) would not have had physical-chemical quality for INMETRO certification purposes.

The parameters with the highest non-compliance levels concerning the limits legally established by the Ministry of Agriculture in the samples of cachaças assessed were copper (15\%) and ethyl carbamate (15\%), and acidity (10\%) and alcohol content (10\%).

Copper is a metal used in the construction of stills that makes a positive contribution to the aroma and flavor of cachaça and has good thermal properties, however, it requires attention with maintenance in order not to leave residues in its distillates since in high concentrations it can have harmful activity for the organism and catalyzes reactions of formation of carcinogenic ethyl carbamate (Silva et al., 2020). The average concentration of this contaminant in the cachaças in this research was $3.8 \mathrm{mg} / \mathrm{L}$, a value that despite meeting what is determined by the legislation is an obstacle to export since international quality standards of distilled beverages limit the copper content at most $2 \mathrm{mg} / \mathrm{L}$ (Santiago et al., 2015).

Ethyl carbamate is mostly formed by the reaction of cyanogenic precursors with ethanol during fermentation and must be controlled by correct distillation (Duarte et al., 2017). The result of research by D'Ávila et al. (2016) with samples of unaged sugarcane spirits distilled in pot stills from Minas Gerais found that all met the legal parameters, but Chreem et al. (2015) researched the physical-chemical quality of 120 collegiate cachaças in Rio de January found that $47 \%$ exceeded the permitted value. A study by Viana et al. (2020) pointed out that the majority of cachaças from Bahia (74\%) had a higher concentration of ethyl carbamate than allowed.

Acidity is a quality parameter intensely perceived by consumers and its control is very important. Its presence in high concentration can be caused by poor hygienic-sanitary conditions or by contamination of the fermentation in which there is a proliferation of bacteria producing organic acids (Viana et al., 2020). 65\% of the samples in this research did not meet the limit defined by INMETRO for certification purposes, a value lower than the $75 \%$ found by Silva et al. (2014) 
Table 1. Results of the physical-chemical analyses of cachaça samples from the State of Paraíba, Brazil.

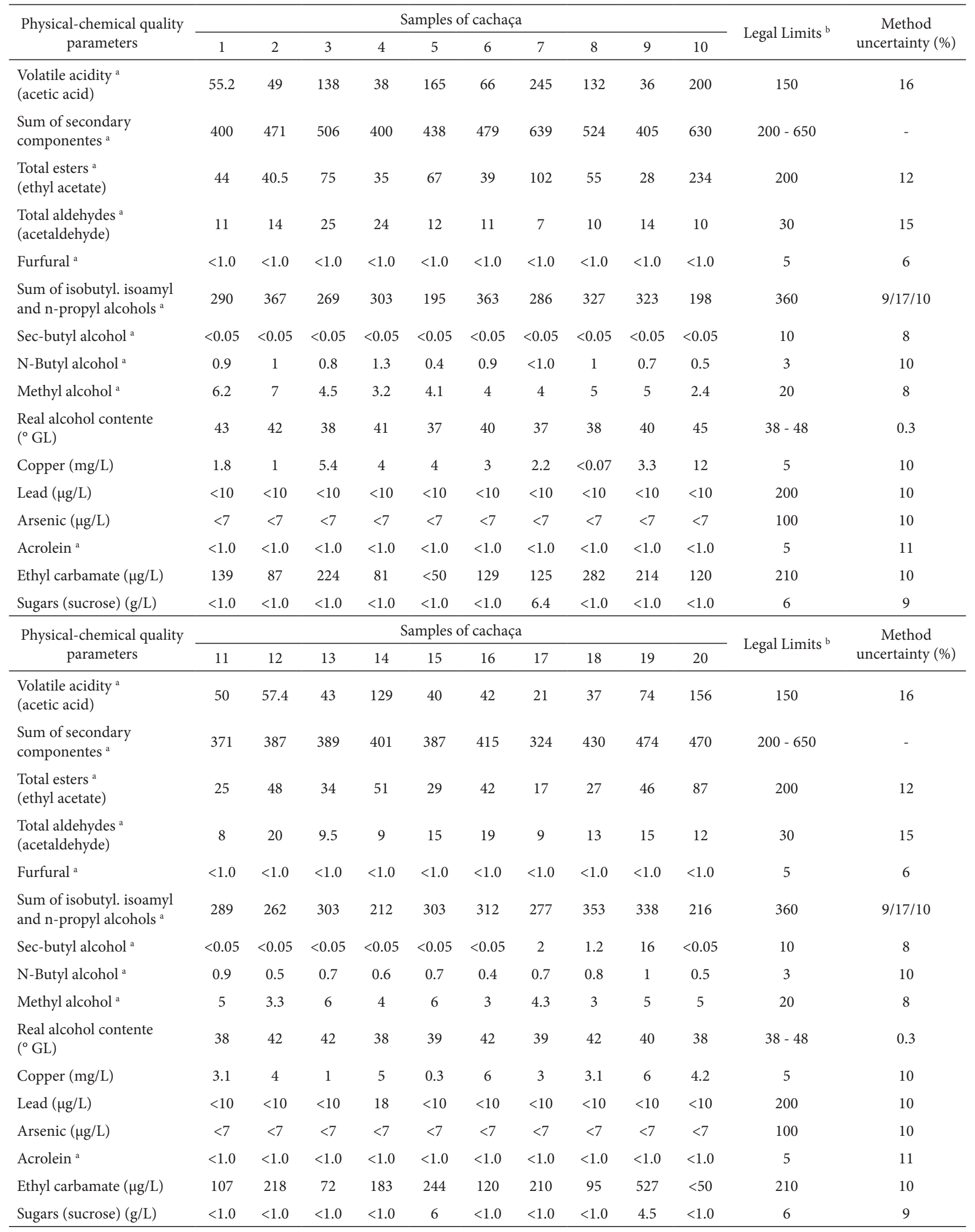

${ }^{\mathrm{a} C}$ Concentration in $\mathrm{mg} / 100 \mathrm{~mL}$ anhydrous alcohol; ${ }^{\mathrm{B} B r a s i l ~(2005 a)}$ combined with Brasil (2014). 
in research with cachaças from Paraíba, but higher than that found by Santiago et al. (2015) in research with cachaças from Minas Gerais produced in six consecutive years, which ranged from 5.6 to $12.4 \%$.

The content of sec-butyl alcohol and total esters were also exceeded in one sample (5.0\% each). High values of this higher alcohol may be due to an incorrect separation of the distillate fractions (Schmidt et al., 2009). In research by Penteado \& Masini (2009) on cachaças from the states of São Paulo and Minas Gerais, this parameter exceeded the limit in $12.1 \%$ of the samples while Duarte et al. (2017) did not find any sample with concentration above the limit allowed in research with organic cachaças from the Paraná, Minas Gerais, Bahia and Ceará states. The content of esters in cachaça increases with the practice of aging in wooden barrels and is related to the sensory improvement of cachaça over time, however an excess of this constituent may indicate an incorrect separation of the fractions of the distillate and brings unwanted taste to the drink (Bortoletto et al., 2016; Duarte et al., 2017). Several studies of physical and chemical quality of cachaças from Minas Gerais (Fernandes et al., 2007; Santiago et al., 2015; Barcelos et al., 2007; Vilela et al., 2007), Rio Grande do Sul (Schmidt et al., 2009) and Paraná (Volpe et al., 2013) demonstrate that this is a common parameter in disagreement with the governamental. The cachaças from the states of Maranhão and Paraná had a percentage of non-compliance with legal regulations regarding the content of esters, much higher than in this research, being 15 and 18\%, respectively limit (Mendes et al., 2016; Duarte et al., 2017). Research has shown that the value of esters in cachaças obtained by column distillers had more than twice the ester content of cachaças distilled in stills, but it is not influenced by the burning of the cane or the storage barrel (Masson et al., 2007; Volpe et al., 2013).

No difference was observed in the average physical-chemical quality of cachaças when grouped by production region. There was no significant correlation between the number of items approved in the physical-chemical analyses and the production capacity of the cachaça facilities assessed.

\subsection{Sensory quality}

The result of the sensory assessment of the cachaça samples is illustrated in Table 2. Half of the samples had a high alcoholic aroma (greater than 4.0), a sensory sensation caused by the absence of floral and fruity characters (Alcarde et al., 2010), typical of the presence of aldehydes with more than ten carbon atoms in the carbon chain, and esters of carboxylic acids with more than five carbon atoms, which promotes the expression of the cachaça alcohol aroma. These aromas are enhanced in distilled alcoholic beverages by aging in wooden barrels (Bortoletto et al., 2018).

Table 2. Sensory assessment of cachaça samples according to each attribute*.

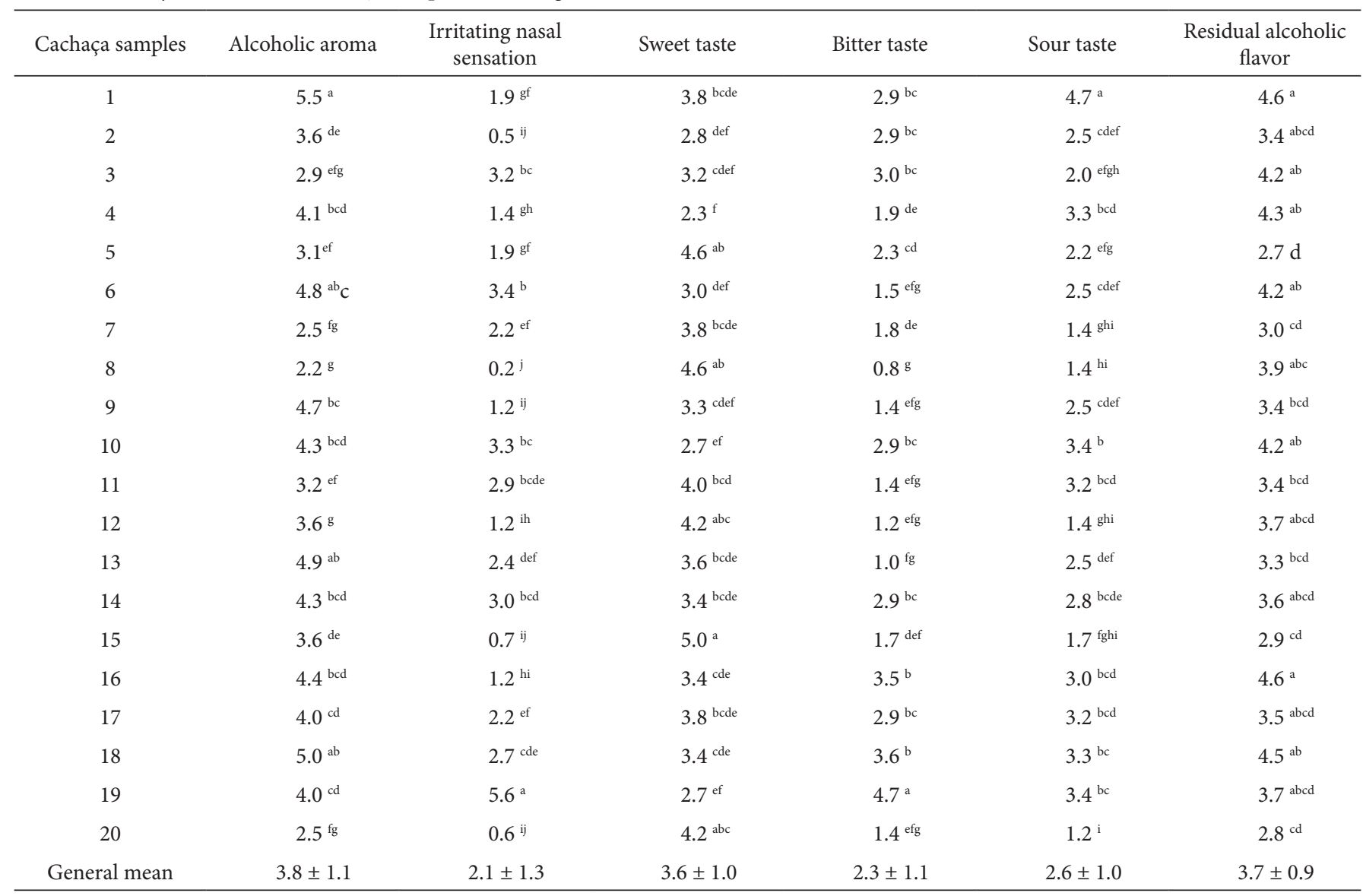

*Scale: 0 = weak; 9 = strong; Equal letters in the same column show equal averages at $95 \%$ significance level. 
Characteristic of high alcoholic aroma is typical of young or redistilled cachaças (Rota et al., 2013).

The irritating nasal sensation, which can be perceived as burning, stinging or pungency, was elevated in samples 3, 6, 10, 14 , and 19. This gustatory perception can be caused by organic acids such as citric, pyruvic, malic, acetaldehyde, and other aliphatic aldehydes with a carbon chain with less than eight carbon atoms, which can be found in higher concentrations in unaged cachaça (Santiago et al., 2016).

When discreet sweet taste is positive for assessing the quality of cachaça; however, with high intensity, it can hide positive flavors for the sensory quality of the drink (Odello et al., 2009). Three cachaças (samples 7, 15 and 19) showed sugars in their physical-chemical composition, but only one of them (sample 19) reported the use of sugar as an ingredient on the label. The perception of the sweetness of the drinks, however, was divergent, and among the sweetest cachaças (samples 5, 8 and 15) two of them were stored in wooden tanks before being bottled. Storing cachaça in wooden containers causes a softening of the flavor, thus reducing the perception of high alcoholic aroma and pungency, typical in freshly distilled cachaças (Duarte et al., 2017; Rota et al., 2013). In particular, we can see in the cachaça sample 19 high values for negative sensory characteristics such as irritating nasal aroma, bitterness and sour and probably for this reason this cachaça was added with sugar. Sweetness should be incorporated into cachaça through aging, but sugar has often been used in order to mask taste defects. Santos \& Faria (2016) observed that aging brought improvements to the taste of cachaça with more intensity than redistillation or addition of sugars.

Many physical-chemical parameters can be related to sensory aspects of distilled alcoholic beverages (Serafim et al., 2013). However, in the present study, only significant positive correlations were found between alcohol content and residual alcohol flavor $(\mathrm{R}=0.5932 ; p<0.0001)$, and between alcoholic content and alcoholic aroma $(\mathrm{R}=0.6829 ; p<0.0001)$. These results indicate that, to manufacture cachaça with these reduced sensory attributes, it would be necessary to use low alcoholic levels, a trend that has been observed in the cachaça Market (Corniani \& Portugal, 2017), in which most producers use alcoholic contents between 40 and $45 \%$. There was also a moderate negative correlation $(\mathrm{R}=-0.5660)$, but significant $(p<0.0001)$, between volatile acidity and alcoholic aroma. This fact can be explained by the presence of volatile acids that, when evaporating, due to intermolecular interactions that facilitate the evaporation of alcohol from cachaça, increase their perception in the aroma (Moreira et al., 2012).

There was no significant difference between the sensory qualities of cachaças according to the different production capacities. The physical-chemical quality (number of parameters of the physical-chemical analysis in compliance with the legislation) and sensory quality did not exhibit a significant correlation, contrary behavior found by Serafim et al. (2013) in research with young and aged cachaças. There was also no correlation between the sensory quality and region of production. This result was contrary to that found by Barcelos et al. (2007) and Mendes et al. (2016) who researched a chemical composition of cachaças from different regions of the states of Minas Gerais and Maranhão, respectively.

\subsection{Evaluation of good manufacturing practices and potential for INMETRO certification}

The results of the GMP assessment and the potential for INMETRO certification are illustrated in Table 3.

On average, $90.8 \%$ of the 177 items of the GMP checklist established by the Ministry of Agriculture were met by cachaça production facilities, with a minimum of $84.8 \%$ and a maximum of $99.4 \%$. These results indicate that producers are currently concerned with complying with what was established by law and by regulatory agencies. A survey of cachaça producers from Brejo Paraibano region in 2012 found only $49.9 \%$ of compliance with the items on the GMP checklist (Ramos et al., 2012). Meneghim et al. (2017) found an increase from 23.3 to $71.9 \%$ in compliance with GMP after technical training of workers from cachaça distilleries from interior of São Paulo.

Table 3. Percentage of compliance with the GMP criteria established by MAPA. and percentage of compliance with INMETRO certification.

\begin{tabular}{|c|c|c|c|c|c|}
\hline \multirow{2}{*}{ Cachaça samples } & \multicolumn{2}{|c|}{ Attendance (\%) } & \multirow{2}{*}{ Cachaça samples } & \multicolumn{2}{|c|}{ Attendance (\%) } \\
\hline & GMP & INMETRO & & GMP & INMETRO \\
\hline 1 & 92.8 & 72.3 & 11 & 87.0 & 42.2 \\
\hline 2 & 99.4 & 87.1 & 12 & 93.8 & 67.7 \\
\hline 3 & 94.0 & 82.4 & 13 & 87.2 & 68.7 \\
\hline 4 & 84.8 & 66.7 & 14 & 85.4 & 63.7 \\
\hline 5 & 85.5 & 62.6 & 15 & 95.6 & 61.5 \\
\hline 6 & 87.3 & 65.8 & 16 & 97.6 & 78.7 \\
\hline 7 & 85.1 & 58.1 & 17 & 96.9 & 78.7 \\
\hline 8 & 95.1 & 73.3 & 18 & 86.5 & 67.7 \\
\hline 9 & 93.9 & 62.3 & 19 & 96.4 & 78.1 \\
\hline 10 & 87.5 & 56.2 & 20 & 93.2 & 68.3 \\
\hline
\end{tabular}


On the other hand, of the 179 items from the checklist prepared based on INMETRO quality requirements for certification purposes, on average, only $68.1 \%$ were met. However, there were cachaça production units that did not meet even half of the requirements. Such low results may be due to the fact that certification was not mandatory. Probably, given that it is voluntary, none of the facilities reached $90 \%$ of compliance with the requirements for certification. There was neither correlation between physical-chemical quality of the cachaças and the percentages of compliance with GMP, nor between that quality and the percentages obtained for INMETRO certification, even so, the adaptation to the GMP is very important for adding value to the product, facilitating exports and providing security to the consumer (Bortoletto et al., 2018).

The sensory quality of cachaças also did not correlate with the fulfillment of GMP and INMETRO requirements. However, cachaça distilleries that had good results in terms of GMP tended also to achieve good results in terms of quality assessment by INMETRO criteria, since there was an important significant correlation ( $\mathrm{R}=0.7555 ; p<0.00001)$ between the percentage of compliance with GMP and compliance with INMETRO criteria. This result differs from the research by Meneghim et al. (2017) who found a positive correlation between adequacy to GMP and sensory quality. In the same work, the researchers found a greater correlation between GMP and sensory quality after the implementation of a training program.

\section{Conclusions}

Only 35\% of the cachaças assessed met the 16 parameters of physical-chemical quality established by INMETRO for certification purposes. Volatile acidity and concentration of ethyl carbamate were the parameters that most caused the failure of the assessed cachaças. The sensory quality of cachaças pointed to the need for greater dedication on the part of producers during storage in wooden barrels before bottling, in order to improve sensory aspects such as alcoholic aroma, irritating nasal sensation, acidic and bitter taste, and residual alcoholic taste. The concern with GMP was very present in the production routine of the cachaça production facilities in the State of Paraíba Brazil. However, that was not the case regarding the requirements of INMETRO for certification purposes, which were not still fully applied. The present study did not find influence of regionality and production capacity on the quality of the drink and production practices.

\section{References}

Alcarde, A. R., Souza, P. A., \& Belluco, A. E. S. (2010). Aspects of the chemical composition and sensorial acceptance of sugar cane spirit aged in casks of different types of woods. Food Science and Technology, 30(Suppl. 1), 226-232. http://dx.doi.org/10.1590/S010120612010000500035.

Barcelos, L. F. V., Cardoso, M. G., Vilela, F. J., \& Anjos, J. P. (2007). Content of ethyl carbamate and other secondary compounds in different spirits produced in three regions of Minas Gerais: south minas, zona da mata and jequitinhonha valley: Zona da Mata, Sul de Minas e Vale do Jequitinhonha. Química Nova, 30(4), 1009-1011. http://dx.doi.org/10.1590/S0100-40422007000400043.
Bortoletto, A. M., Correa, A. C., \& Alcarde, A. R. (2016). Aging practices influence chemical and sensory quality of cachaça. Food Research International, 86, 46-53. http://dx.doi.org/10.1016/j.foodres.2016.05.003.

Bortoletto, A. M., Silvello, G. C., \& Alcarde, A. R. (2018). good manufacturing practices, hazard analysis and critical control point plan proposal for distilleries of cachaça. Scientia Agrícola, 75(5), 432-443. http://dx.doi.org/10.1590/1678-992x-2017-0040.

Brasil, Ministério da Agricultura, Pecuária e Abastecimento. (2005a, June 30). Regulamento técnico para fixação dos padrões de identidade e qualidade para aguardente de cana e para cachaça (Instrução normativa $\mathrm{n}^{\circ} 13$, de 29 de junho de 2005). Diário Oficial [da] República Federativa do Brasil.

Brasil, Ministério da Agricultura, Pecuária e Abastecimento. (2005b, September 20). Aprova o manual operacional de bebidas e vinagres (Instrução normativa $n^{\circ} 24$, de 8 de setembro de 2005). Diário Oficial [da] República Federativa do Brasil.

Brasil. Ministério do Desenvolvimento, Indústria e Comércio Exterior, Instituto Nacional de Metrologia, Normalização e Qualidade Industrial - INMETRO. (2009, September 25). Aprova a revisão dos Requisitos de Avaliação da Conformidade para Cachaça (Portaria $\mathrm{n}^{\circ}$ 276, de 24 de setembro de 2009). Diário Oficial [da] República Federativa do Brasil. Retrieved from http://www.inmetro.gov.br/ legislacao/rtac/pdf/RTAC001497.pdf

Brasil, Ministério da Agricultura, Pecuária e Abastecimento. (2014, August 11). Altera o subitem 5.1.2. do Anexo da Instrução Normativa n. 13, de 29 de junho de 2005 (Instrução Normativa n 28, de 8 de agosto de 2014). Diário Oficial [da] República Federativa do Brasil.

Chreem, D. R., Riachi, L. G., Moreira, R. F. A., \& De Maria, C. A. B. (2015). A study of the ethyl carbamate level in cachaça samples. International Food Research Journal, 22(1), 345-349. Retrieved from http://www.ifrj.upm.edu.my/22\%20(01)\%202015/(51).pdf

Corniani, L. S., \& Portugal, C. B. (2017). A lapidação da qualidade da cachaça. Engarrafador Moderno, 279, 28-31. Retrieved from https:// engarrafadormoderno.com.br/processos/a-lapidacao-da-qualidade

Coutinho, E. P., Ramos, Z. N. S., Alves, A. S., \& Oliveira, R. E. S. (2012). Good manufacturing practices of cachaça from the Alembic: technical and business view. Journal of Health Sciences, 14(3), 165-170. http:// dx.doi.org/10.17921/2447-8938.2012v14n3p\%25p.

D’Ávila, G. B., Cardoso, M. G., Santiago, W. D., Rodrigues, L. M. A., Silva, B. L., Cardoso, R. R., Caetano, A. R. S., Ribeiro, C. F. S., \& Nelson, D. L. (2016). Quantification of ethyl carbamate in cachaça produced in different agro-industrial production systems. Journal of the Institute of Brewing, 122(2), 299-303. http://dx.doi.org/10.1002/jib.322.

Dornelles, A. S., Rodrigues, S., \& Garruti, D. S. (2009). Acceptance and sensory profile of cachaça produced using Kefir and Saccharomyces cerevisae. Food Science and Technology, 29(3), 518-522. http://dx.doi. org/10.1590/S0101-20612009000300010.

Duarte, F. C., Cardoso, M. G., Pinheiro, A. C. M., Santiago, W. D., \& Carvalho, L. L. (2012). Physicochemical and sensory changes in aged sugarcane spirit submitted to filtering with activated carbon filter. Food Science and Technology, 32(3), 471-477. http://dx.doi. org/10.1590/S0101-20612012005000070.

Duarte, F. C., Cardoso, M. G., Santiago, W. D., Machado, A. M. R., \& Nelson, D. L. (2017). Brazilian organic sugarcane spirits: Physicochemical and chromatographic profile. Ciência Agronômica, 48(2), 288-295. http://dx.doi.org/10.5935/1806-6690.20170033.

Fernandes, W. J., Cardoso, M. G., Vilela, F. J., Morais, A. R., Silva, V. F., \& Nelson, D. L. (2007). Physicochemical quality of a blend of domestic cachaças from the South of Minas Gerais. Journal of Food Composition and Analysis, 20(3-4), 257-261. http://dx.doi. org/10.1016/j.jfca.2006.01.012. 
Instituto Adolfo Lutz - IAL. (2008). Normas analíticas, métodos químicos e físicos para análise de alimentos (4. ed., Vol. 4). São Paulo: IAL. Retrieved from http://www.ial.sp.gov.br/resources/editorinplace/ ial/2016_3_19/analisedealimentosial_2008.pdf

Instituto Brasileiro da Cachaça - IBRAC. (2019, February 6). Notícias do IBRAC. Retrieved from http://www.ibrac.net/index.php/noticias/ noticias-do-ibrac

Masson, J., Cardoso, M. G., Vilela, F. J., Pimentel, F. A., Morais, A. R., \& Anjos, J. P. (2007). Parâmetros físico-químicos e cromatográficos em aguardentes de cana queimada e não queimada. Ciência $e$ Agrotecnologia, 31(6), 1805-1810. http://dx.doi.org/10.1590/S141370542007000600030 .

Mendes, N. E. Fo., Mouchrek, V. E. Fo., Castro, A. C., \& Martins, V. M. (2016). Characterization of the artisanal brandies of sugarcane produced in the regions of Alpercatas and Sertão Maranhense. Revista Virtual de Química, 8(5), 1421-1432. http://dx.doi.org/10.21577/19846835.20160100.

Meneghim, M. C., Barbosa, R. A. B., Ramalheiro, G. C. F., \& Lorenzo, H. C. (2017). Boas práticas de fabricação e a melhora da qualidade na agricultura familiar: estudo de caso com pequenos produtores de cachaça. Retratos de Assentamentos, 20(1), 207-231. http://dx.doi. org/10.25059/2527-2594/retratosdeassentamentos/2017.v20i1.263.

Moreira, R. F. A., Netto, C. C., \& De Maria, C. A. B. (2012). The volatile fraction of sugar cane spirits produced in Brazil. Quimica Nova, 35(9), 1819-1826. http://dx.doi.org/10.1590/S0100-40422012000900022.

Odello, L., Braceschi, G. P., Seixas, F. R. F., Silva, A. A., Galinaro, C. A., \& Franco, D. W. (2009). Sensory evaluation of cachaça. Quimica Nova, 32(7), 1839-1844. http://dx.doi.org/10.1590/S010040422009000700029.

Oliveira, R. E. S., Silva, M. J., Coutinho, E. P., Moreira, R. T., \& Cruz, G. R. B. (2012). Profile and habits of consumers of cachaça in the State of Paraíba. Semina: Ciências Agrárias, 33(1), 259-270. http:// dx.doi.org/10.5433/1679-0359.2012v33n1p259.

Penteado, J. C. P., \& Masini, J. C. (2009). Heterogeneity of secondary alcohols in brazilian sugar cane spirits from diverse origins and processes of manufacture. Quimica Nova, 32(5), 1212-1215. http:// dx.doi.org/10.1590/S0100-40422009000500024.

R Core Team. (2018). R: a language and environment for statistical computing. Vienna: R Foundation for Statistical Computing. Retrieved from https://www.R-project.org/

Ramos, Z. N. S., Alves, A. S., Oliveira, R. E. S., \& Coutinho, E. P. (2012). Diagnóstico das Boas Práticas de Fabricação em unidades produtoras de cachaça de alambique do Brejo Paraibano. Higiene Alimentar, 26(212-213), 76-80. Retrieved from http://higienealimentar.com. br/wp-content/uploads/2019/07/revista-212-213.pdf

Rota, M. B., Piggott, J. R., \& Faria, J. B. (2013). Sensory profile and acceptability of traditional and double-distilled cachaça aged in oak casks. Journal of the Institute of Brewing, 119(4), 251-257. http:// dx.doi.org/10.1002/jib.88.
Santiago, W. D., Cardoso, M. G., Zacaroni, L. M., Rodrigues, L. M. A., Duarte, F. C., Ribeiro, C. F. S., \& Nelson, D. L. (2015). Multivariate analysis for the characterization of physico-chemical profiles of cachaça produced in cooper stills over a period of six years in Minas Gerais state. Journal of the Institute of Brewing, 121(2), 244-250. http://dx.doi.org/10.1002/jib.216.

Santiago, W. D., Cardoso, M. G., Santiago, J. A., Teixeira, M. L., Barbosa, R. B., Zacaroni, L. M., Sales, P. F., \& Nelson, D. L. (2016). Physicochemical profile and determination of volatile compounds in cachaça stored in new oak (Quercus sp.), amburana (Amburana cearensis), jatoba (Hymenaeae carbouril), balsam (Myroxylon peruiferum) and peroba (Paratecoma peroba) casks by SPME-GC-MS. Journal of the Institute of Brewing, 122(4), 624-634. http://dx.doi.org/10.1002/jib.372.

Santos, V. R., \& Faria, J. B. (2016). The effect of sugar addition and the ageing process on the sensory quality of sugarcane spirit samples obtained traditionally and by redistillation. Brazilian Journal of Food Technology, 19, 1-8. http://dx.doi.org/10.1590/1981-6723.7015.

Schmidt, L., Marmitt, S., Oliveira, E. C., \& Souza, C. F. V. (2009). Physicochemical properties of spirits produced artisanally in the Region of Vale do Taquari in Rio Grande do Sul. Alimentos e Nutrição, 20(4), 539-551. Retrieved from http://serv-bib.fcfar.unesp.br/seer/ index.php/alimentos/article/view/1205

Serafim, F. A. T., Seixas, F. R. F., Silva, A. A., Galinaro, C. A., Nascimento, E. S. P., Buchviser, S. F., Odello, L., \& Franco, D. W. (2013). Correlation between chemical composition and sensory properties of Brazilian sugarcane spirits (cachaças). Journal of the Brazilian Chemical Society, 24(6), 973-982. http://dx.doi.org/10.5935/0103-5053.20130125.

Silva, J. H. N., Verruma-Bernardi, M. R., Medeiros, S. D. S., \& Oliveira, A. L. (2020). Monitoring the content of ethyl carbamate and copper in organic and conventional cachaça. Scientia Agrícola, 77(5), e20190027. http://dx.doi.org/10.1590/1678-992x-2019-0027.

Silva, M. J., Moreira, R. T., Coutinho, E. P., Cruz, G. R. B., \& Sousa, J. R. T. (2014). Physical-chemical and sensorial characteristics of Distilled cachaças produced in the brejo Micro-region of paraíba, PB. Revista Brasileira de Produtos Agroindustriais, 16(4), 445-451. http://dx.doi.org/10.15871/1517-8595/rbpa.v16n4p445-451.

Viana, E. J., Tavares, I. M. C., Rodrigues, L. M. A., Cardoso, M. G., Baffa, J. C. Jr., Gualberto, S. A., \& Oliveira, C. P. (2020). Evaluation of toxic compounds and quality parameters on the aged Brazilian sugarcane spirit. Research. Social Development, 9(8), e395985544. http://dx.doi.org/10.33448/rsd-v9i8.5544.

Vilela, F. J., Cardoso, M. G., Masson, J., \& Anjos, J. P. (2007). Determination of the physical-chemical composition of homemade cachaças produced in the South of Minas Gerais and their mixtures. Ciência e Agrotecnologia, 31(4), 1089-1094. http://dx.doi.org/10.1590/S141370542007000400022.

Volpe, T. C., Bona, E., \& Vitório, E. C. (2013). Evaluation of physicochemical characteristics from industrial and handcrafted cachaça commercialized in the north central region from Paraná State. Brazilian Journal of Food Research, 4(2), 55-65. http://dx.doi. org/10.14685/rebrapa.v4i2.114. 